\title{
Correction to: Cytokine storm and histopathological findings in 60 cases of COVID-19-related death: from viral load research to immunohistochemical quantification of major players IL-1 $\beta$, IL-6, IL-15 and TNF-a
}

\author{
Paolo Frisoni ${ }^{1} \cdot$ Margherita Neri $^{1} \cdot$ Stefano D'Errico $^{2} \cdot$ Letizia Alfieri $^{1} \cdot$ Diana Bonuccelli ${ }^{3}$. Mariano Cingolani ${ }^{4}$. \\ Marco Di Paolo ${ }^{5} \cdot$ Rosa Maria Gaudio ${ }^{6} \cdot$ Maurizio Lestani $^{7} \cdot$ Matteo Marti $^{6} \cdot$ Massimo Martelloni $^{3} \cdot$ Carlo Moreschi $^{8}$. \\ Alessandro Santurro ${ }^{9} \cdot$ Matteo Scopetti $^{9} \cdot$ Ombretta Turriziani ${ }^{10} \cdot$ Martina Zanon $^{2} \cdot$ Roberto Scendoni $^{4} \cdot$ Paola Frati $^{9}$. \\ Vittorio Fineschi ${ }^{9}$
}

Published online: 15 December 2021

(c) The Author(s) 2021

\section{Correction to: Forensic Science, Medicine and Pathology https://doi.org/10.1007/s12024-021-00414-9}

The original version of this article unfortunately contained mistakes. Tables $1-4$ are missing in the published version.

The original article has been corrected.

Open Access This article is licensed under a Creative Commons Attribution 4.0 International License, which permits use, sharing, adaptation,

The original article can be found online at https://doi.org/10.1007/ s12024-021-00414-9.

Vittorio Fineschi

vittorio.fineschi@uniroma1.it

Massimo Martelloni

martellonimassimo.prof@gmail.com

Carlo Moreschi

carlo.moreschi@uniud.it

Alessandro Santurro

alessandro.santurro@uniroma1.it

Matteo Scopetti

matteo.scopetti@uniroma1.it

Ombretta Turriziani

ombretta.turriziani@uniroma1.it

Martina Zanon

martina.zanon@virgilio.it

Roberto Scendoni

r.scendoni@unimc.it

Paola Frati

paola.frati@uniroma1.it

1 Department of Medical Sciences, University of Ferrara, Ferrara, Italy distribution and reproduction in any medium or format, as long as you give appropriate credit to the original author(s) and the source, provide a link to the Creative Commons licence, and indicate if changes were made. The images or other third party material in this article are included in the article's Creative Commons licence, unless indicated otherwise in a credit line to the material. If material is not included in the article's Creative Commons licence and your intended use is not permitted by statutory regulation or exceeds the permitted use, you will need to obtain permission directly from the copyright holder. To view a copy of this licence, visit http://creativecommons.org/licenses/by/4.0/.

Publisher's Note Springer Nature remains neutral with regard to jurisdictional claims in published maps and institutional affiliations.

2 Department of Surgical, Medical and Health Sciences, University of Trieste, Trieste, Italy

3 Department of Legal Medicine, Territorial Unit USL Toscana Nordovest Lucca, Pisa, Italy

4 Department of Law, Institute of Legal Medicine, University of Macerata, Macerata, Italy

5 Department of Surgical Pathology, Medical, Molecular and Critical Area, Institute of Legal Medicine, University of Pisa, 56126 Pisa, PI, Italy

6 Department of Translational Medicine, University of Ferrara, Ferrara, Italy

7 Pathology Unit, Territorial Unit ULSS 7 Pedemontana, Alto Vicentino Hospital, Thiene, Italy

8 Department of Medical Area (DAME), University of Udine, Udine, Italy

9 Department of Anatomical, Histological, Forensic and Orthopaedic Sciences (SAIMLAL), Sapienza University of Rome, Rome, Italy

10 Department of Molecular Medicine, Laboratory of Virology, Sapienza University of Rome, Rome, Italy 